\title{
Safety and Efficacy of Immunomodulators and Biologics During Pregnancy and Lactation for the Treatment of Inflammatory Bowel Disease
}

\author{
Sumona Saha, M.D. and \\ Assistant Professor of Medicine, Division of Gastroenterology and Hepatology, University of \\ Wisconsin School of Medicine and Public Health, UW Medical Foundation Centennial Building, \\ Room 4224, 1685 Highland Avenue, Madison, WI 53705, Phone: 608-263-1995, Fax: \\ 608-265-5677, ssaha@medicine.wisc.edu
}

Arnold Wald, M.D.

Professor of Medicine, Division of Gastroenterology and Hepatology, University of Wisconsin School of Medicine and Public Health, UW Medical Foundation Centennial Building, Room 4215, 1685 Highland Avenue, Madison, WI 53705, Phone: 608-263-1995, Fax: 608-265-5677, axw@medicine.wisc.edu

\begin{abstract}
Introduction-The inflammatory bowel diseases (IBD) are chronic, idiopathic, inflammatory conditions of the gastrointestinal tract that peak in incidence during the reproductive years. Therefore, the safety of IBD medications during pregnancy and lactation is of significant interest to many patients. Unfortunately, the current pregnancy labeling used by the United States Food and Drug Association (FDA) is often misinterpreted and may mislead healthcare providers and their patients to believe that risk increases from category $A$ to $B$ to $C$ to $D$ to $X$ which, in fact, is not the case. In addition, the FDA categories do not always distinguish between risks based on human versus animal data or between differences in frequency, severity, and type of fetal developmental toxicities. Thus, providers should not rely solely on the FDA category labels when making medication choices in pregnant and lactating women and should instead be familiar with the primary safety data for the medications they prescribe.
\end{abstract}

Areas Covered-This article will discuss general safety data and safety classifications for medication use in pregnancy. It will also provide an in-depth review of the available safety data during pregnancy and lactation for the more potent immunosuppressants used to treat IBD: the immunomodulators and biologics. Lastly, it will include the authors' expert opinions on the use of these medications during these critical periods.

Expert Opinion-The benefit-to-risk ratio for most immunomodulators and biologics used in the treatment of IBD favors medication continuation during pregnancy. Certain immunomodulators, however, can cause extreme fetal harm and should be used with caution in all individuals of reproductive potential. While human safety data regarding teratogenesis and some data on pregnancy outcomes exist for most IBD medications, long-term follow-up studies of children and young adults exposed to these drugs in utero are lacking. These studies are needed to determine if these drugs are of sufficiently low risk to be considered safe.

Correspondence to: Arnold Wald.

DECLARATION OF INTEREST The authors state no conflict of interest with regards to this manuscript. 


\section{Keywords}

Inflammatory bowel disease; Crohn's disease; ulcerative colitis; pregnancy; lactation; immunomodulators; biologics

\section{INTRODUCTION}

The inflammatory bowel diseases (IBD) are chronic, idiopathic, inflammatory conditions of the gastrointestinal tract. The term IBD refers to two main entities: Crohn's disease (CD) and ulcerative colitis (UC). Although IBD affects persons of all ages, the peak incidence of IBD occurs between the ages of 20 to 40 , which is the period of maximal fertility $(1,2)$. Thus, reproductive issues are of great concern to younger patients and their physicians. Both are often concerned about the effect of IBD medications on fertility as well as potential effects of medication on the developing fetus and the breastfed newborn.

Given the prevalence of the use of immunomodulators and biologics in the treatment of IBD, decisions must often be made regarding whether these drugs should be continued in patients considering pregnancy or who are already pregnant. Women must also decide if they should be continued during lactation. Physicians who counsel women about the safety of medications during pregnancy must be aware that pregnant women with active $\mathrm{CD}$ and UC are at increased risk for such complications of pregnancy as pre-term birth (3) and that women with IBD are at higher risk for delivering low birth weight infants and undergoing Cesarean section independent of their disease activity $(3,4)$. Stopping medications before or during pregnancy significantly increases the risk for reactivation of disease within one year and therefore the risk for an adverse pregnancy outcome. Thus, the potential benefits of drug discontinuation during pregnancy and lactation must be carefully weighed against its risks.

This article will discuss general safety data and safety classifications for medication use in pregnancy. It will also provide an in-depth review of the available safety data for immunomodulators and biologics for the treatment of IBD in pregnancy and lactation. Lastly, it will conclude with the authors' expert opinion on the use of these medications during these critical periods.

\subsection{Medication Safety in Pregnancy}

Very few drugs have been studied thoroughly for safety in human pregnancy due to the long, and costly nature of the studies that are needed to assess the effects of in utero drug exposure on fetal development and early childhood neurologic development, behavior, and organ function. Thus, few drugs can be described as completely safe in pregnancy. In most cases, clinicians must rely on animal data and retrospective studies to determine a drug's safety profile in pregnancy.

The U.S. Food and Drug Administration (FDA) does provide clinicians with some guidance regarding the use of medications in pregnancy, using a letter category system (Table 1) (5). The FDA issues a pregnancy category for each drug at the time of its approval for general use. These categories reflect a summary of the data on teratogenicity in animals, and when available, data in humans. Unfortunately, these categories do not reflect the clinical contexts for which the drugs are prescribed, the usual doses prescribed in humans, or post marketing safety surveillance data. Furthermore, they are often misinterpreted by patients and physicians to be a simple grading system. Due to its limitations, the FDA is considering the elimination of the letter category system. The proposed new labeling format will be based on the most relevant scientific data available and be designed to help health care providers 
counsel pregnant women, nursing women, and all women of reproductive age about the use of prescription drugs including biologics (6).

\subsection{Medications used to treat IBD}

Various classes of medications are used to treat IBD. Traditionally, a "step-up" approach has been used in which the least toxic, and perhaps least potent, medications are used before moving to more potent immunosuppressants. This approach is now being challenged, as a pivotal study involving patients with moderate-to-severe $\mathrm{CD}$ has shown that patients with relatively newly diagnosed CD treated with a "top down" approach had higher rates of steroid-free remission compared with patients treated by the more conventional approach (7).

There is less controversy about the safety of the lower-tier classes of medications used in the "step-up" approach to treat IBD during pregnancy and lactation compared to the immunomodulators and biologics. Nonetheless, it is worth noting some of the issues associated with their use during these vulnerable periods. Table 2 summarizes the pregnancy and lactation considerations for the medications used most commonly to treat IBD.

The aminosalicylates (sulfasalazine, mesalamine, and balsalazide) are used widely to treat IBD affecting the colon. With the exception of olsalazine and a particular formulation of mesalamine (Asacol $\left.{ }^{\circledR}\right)$, they are all FDA category B and are considered to be low risk in pregnancy (8). Sulfasalazine use is not contraindicated in the pregnant woman, however, sufficient folic acid should be taken to reduce the risk for neural tube defects given its inhibitory effect on folate metabolism. It is recommended that women who are pregnant or considering pregnancy take $2 \mathrm{mg}$ of supplemental folate daily (9). In males, sulfasalazine use is associated with reversible oligospermia and adverse change in sperm motility and morphology $(10,11,12)$. It is recommended that men taking sulfasalazine discontinue the drug for at least 3 months before attempting conception and substitute the drug with another mesalamine product.

Corticosteroids have been used extensively for the treatment of various inflammatory conditions in pregnancy. Many epidemiologic studies have reported an increased risk for orofacial clefts in exposed newborns. (13-19). Other studies however, suggest, only minimal teratogenicity (20). Corticosteroids are labeled category $\mathrm{C}$ by the FDA in pregnancy. In addition to monitoring for general side effects, pregnant women on corticosteroids should be monitored closely for hypertension and gestational diabetes mellitus (21). Similarly, infants exposed to corticosteroids later in gestation should be monitored for adrenal suppression. As the use of corticosteroids poses a small risk to the developing infant,they should be reduced to the lowest possible dose necessary to keep the mother in disease remission.

Antibiotics are used occasionally to treat IBD. The antibiotics used most commonly in the treatment of IBD are ciprofloxacin (FDA category C) and metronidazole (FDA category B). These antibiotics can be used safely for short periods of time during pregnancy; however, prolonged use is not recommended.

\section{IMMUNOMODULATORS}

\subsection{Thiopurines}

Pregnancy-The thiopurines (FDA category D), azathioprine and its pro-drug 6mercaptopurine (6-MP) are used for maintenance of remission in patients with moderate IBD. The biological effects of thiopurines are thought to be mediated by competition of 6thioguanine nucleotides (6-TGNs), a thiopurine metabolite, with endogenous DNA nucleotides. This, in turn, impedes the proliferation of $\mathrm{T}$ and $\mathrm{B}$ lymphocytes and suppresses 
the overactive immune system in patients with IBD (22). In addition, thiopurine metabolites are thought to inhibit interferon $\gamma$, a significant mediator of intestinal inflammation (23).

With regards to safety in pregnancy, some animal studies have demonstrated teratogenicity, including increased frequencies of cleft palate, open-eye and skeletal anomalies in mice exposed to azathioprine. These animals were exposed to the equivalent of 4 to 13 times the maximum human therapeutic dose $(24,25)$ during the period of organogenesis. In contrast, other studies in mice during organogenesis using doses of azathioprine no higher than twice the therapeutic range for humans did not find an increased risk for malformations . They did, however, show higher rates of miscarriage and growth retardation. Similarly 6-MP has also been shown to be teratogenic in in rats exposed to supra-therapeutic doses (26) with increased frequencies of cleft palate, skeletal,and urogenital anomalies, and diaphragmatic hernia reported $(27,28)$. When 6-MP was given orally at no more than 12 times the maximum human dose, no fetal malformations were seen (29).

In a recent study, thiopurine use by pregnant women for a variety of conditions, including IBD, was not associated with an increased risk of fetal malformations compared to the general population $(\mathrm{p}=.775$; OR 1.17 ; CI: $0.37,3.69)$. Similarly, data from women who have undergone solid-organ transplantation have neither reported higher rates of malformations (30) nor any consistent patterns of congenital anomalies $(31,32)$.

A study of 485 pregnant women with IBD on 6-MP before or at conception showed neither an increased risk for congenital abnormalities, nor an increased risk for preterm delivery, spontaneous abortion, neoplasia or infections (33). Similarly, case series of women with IBD on azathioprine have found the risk of congenital anomalies to be no higher than in the general population $(34,35)$. Nevertheless, a recent study using the Swedish Birth Registry of azathioprine exposure during early pregnancy in 476 women of which 300 had IBD, found a 3 -fold increased risk for ventricular/atrial septal defects with drug exposure. The odds ratio (OR) for cardiac defects after adjusting for maternal characteristics was 3.18 (95\% CI: 1.456.04) (36). In addition, the overall rate of congenital malformations was $6.2 \%$ in the azathioprine group compared with $4.7 \%$ among controls (adjusted OR: 1.41 ; 95\% CI: $0.98-$ 2.04). Thus, the authors concluded that infants exposed to azathioprine in early pregnancy may be at a moderately increased risk of congenital malformations with the caveat that the true risk remains unknown as the severity of maternal illness may confound the association.

Transplacental transfer of the thiopurines does occur, however, fetuses are thought to be protected from their potential harmful effects due to their low oral bioavailability and the barrier effects of the placenta. On average, $47 \%$ of orally administered AZA is available to the systemic circulation $(37,38)$. The bioavailability of 6-MP is much lower, with only $16 \%$ of an oral dose of 6-MP entering the systemic circulation (39). With regards to the placenta as a barrier, a small case series by de Boer et al. found undetectable levels of the thiopurine metabolite, 6-methylmercaptopurine (6-MMP) and lower concentrations of 6-TGN in infants exposed to azathioprine in utero than in the mother (40). Absence of inosinate pyrophosphorylase, an enzyme involved in the metabolism of the thiopurines, in the early fetal liver, may further protect the fetus during the critical period of organogenesis (41).

Thus, based on the experience in transplantation and IBD patients, as well as their pharmacokinetics and metabolism, thiopurines are often continued during pregnancy to maintain remission. Withdrawal of thiopurines increases the risk of relapse which may be more deleterious to neonatal outcomes than any potential risk from the medications (42). Nevertheless, more studies measuring levels of the thiopurines and their metabolites in exposed newborns are needed. 
Lactation-Breastfeeding by mothers who are on thiopurines is not recommended by the American Academy of Pediatrics (AAP) due to the hypothetical risk of immunosuppression in the exposed neonate. This recommendation does not reflect the results of recent studies which suggest that the transfer of azathioprine and 6-MP via breast milk is exceedingly low (43) and that no deleterious consequences of this low-level transfer in the newborn have been found (44).

\subsection{Methotrexate}

Pregnancy-Methotrexate is used in the treatment of moderate or refractory CD (45). Its efficacy in UC has yet to be established. As it is clearly teratogenic, it is FDA category X and should not be used in women or men considering conception. Methotrexate is a folic acid antagonist. Its use during the critical period of exposure, believed to be between 6 and 8 weeks after conception, at a dose of $10 \mathrm{mg}$ per week or higher is absolutely contraindicated, although abnormalities have been reported with all dosage levels and timing of exposure (46). Methotrexate use in pregnancy is associated with multiple congenital anomalies collectively called methotrexate embryopathy or fetal aminopterin-methotrexate syndrome (47). The syndrome is characterized by intrauterine growth retardation, decreased ossification of the calvarium, hypoplastic supraorbital ridges, small, low-set ears, micrognathia, limb abnormalities and sometimes mental retardation. Exposure in the $2^{\text {nd }}$ and $3^{\text {rd }}$ trimesters is also harmful and may be associated with fetal toxicity and mortality (48). Women of childbearing potential exposed to methotrexate should use an adequate form of contraception. If considering pregnancy, women on methotrexate should discontinue the drug at least 6 months before attempting conception (49).

In men, methotrexate may cause reversible oligospermia (50). There have been no studies, however, documenting an increased risk of congenital anomalies in the offspring of men on methotrexate $(51,52,53)$. Since one cycle of spermatogenesis requires 74 days, it is recommended that men wait a minimum of 3 months after discontinuing methotrexate before attempting to conceive (54).

Lactation-Methotrexate is excreted into breast milk at low levels. Concentrations of methotrexate in milk have been found to be less than $10 \%$ of those in plasma (55). Although the clinical significance of this is not known, given the absence of safety data and the potential danger of accumulation within neonatal tissues, the AAP does not recommend breast feeding by mothers who are on methotrexate (56).

\subsection{Thalidomide}

Pregnancy-Thalidomide has been shown in prospective trials to be effective in refractory $\mathrm{CD}(57,58)$. It is believed to improve symptoms of $\mathrm{CD}$ either via its anti-tumor necrosis factor (TNF)-a effects and/or its antiangiogenic properties (59). Like methotrexate, thalidomide is FDA category $\mathrm{X}$ as its teratogenicity has been extensively documented. Anomalies associated with thalidomide include limb defects, central nervous system effects, and abnormalities of the respiratory, cardiovascular, gastrointestinal and genitourinary system (48).

Pregnancy is contraindicated in women recently exposed to thalidomide. Given that the halflife of thalidomide is 8.7 hours, the Organization of Teratology Information Specialists (OTIS) recommends discontinuing thalidomide at least one month before conception to reduce the risk of thalidomide-related birth defects (60). The effect on pregnancy outcomes from distant thalidomide use is not known, as all reported infants with thalidomide-related birth defects had exposure to the drug in the first trimester. 
To monitor access to thalidomide and prevent teratogenicity, prescription of the drug in the U.S. requires registration by both the prescribing physician and the dispensing pharmacy with the System for Thalidomide Education and Prescribing Safety (STEPS) program (61, 62). Per the program, women of childbearing age must undergo pregnancy testing before starting therapy and every 2 to 4 weeks during treatment. They either must abstain from sexual intercourse or use 2 highly effective contraceptive methods during treatment. Men must abstain from sexual intercourse or use a condom during treatment, even if they have undergone a successful vasectomy.

Lactation-Thalidomide has not been studied during breastfeeding; however, based on its chemical properties, breast milk transfer is likely. Infants exposed to thalidomide through breast milk may exhibit drowsiness. Given the absence of safety data, women on thalidomide should be advised not to breastfeed (60).

\subsection{Cyclosporine}

Pregnancy-Cyclosporine is a calcineurin inhibitor which has been used to treat steroidrefractory UC. It inactivates the nuclear factor of activated T cells, inhibits the expression of CD40 ligand, and prevents the stimulation of dendritic cells by tumor necrosis factor (TNF)a (63). In patients with ulcerative colitis, cyclosporine also has been demonstrated to suppress interleukin (IL)-2 and IL-3 production, inhibit chemotaxis of neutrophils and induce apoptosis in T cells $(63,64)$. Most commonly, it is initiated in the hospital setting as an alternative to colectomy $(65,66)$. Due to the potential complications of cyclosporine which include hypertension, nephrotoxicity, opportunistic infections, and death, it is recommended that cyclosporine be used as a bridge to maintenance therapy with azathioprine or 6-MP (67) after an approximately 3 month period of overlap. Although cyclosporine crosses the placenta, it has not been found to be teratogenic in animal models $(68,69)$. Cyclosporine is designated as FDA category $\mathrm{C}$ in pregnancy.

The largest experience with cyclosporine use in pregnancy is found in the transplant literature. A meta-analysis of 410 pregnancies from 15 studies concerning pregnancy outcomes after cyclosporine therapy reported an increased incidence in major malformations which could have been due to chance alone, $(\mathrm{OR}=3.83,95 \%$ confidence interval: $0.75-19.6)$. No increase in preterm births or low birth weights, however, was found (70).

Published studies of cyclosporine use in pregnant women with IBD are limited. Although no congenital malformations have been reported, preterm birth and low birth weight have been reported $(71,72,73)$. Whether these outcomes are a reflection of the severity of the mother's underlying disease or of medication effects is not clear.

Lactation-Cyclosporine is transferred at high levels into breast milk; however, no adverse effects have been reported in published case reports and case series of breastfed infants exposed to cyclosporine $(74,75)$. Nevertheless, the AAP advises against breastfeeding while on cyclosporine due to potential alterations in cellular metabolism in the newborn (76).

\subsection{Tacrolimus}

Pregnancy-Tacrolimus, like cyclosporine, is also a potent calcineurin inhibitor. It blocks the $\mathrm{Ca}^{+} /$calmodulin-dependent serine/threonine phosphatase required for early $\mathrm{T}$ cell activation and thereby decreases inflammation (77). It has been used successfully to treat both refractory UC and CD. The side effect profile of tacrolimus is nearly identical to that of cyclosporine although certain side effects such as hypertension, gingival hyperplasia and hypertrichosis are less pronounced in tacrolimus versus cyclosporine treated patients (78). Like cyclosporine, tacrolimus is FDA category $\mathrm{C}$ for pregnant women. 
The published experience with tacrolimus use in pregnancy most often involves posttransplant patients and has been largely favorable (79). In an analysis of 100 pregnancies involving 84 women who had undergone solid organ transplantation, there were 3 cases of neonatal death and 4 cases of congenital malformations which did not exhibit a consistent pattern (80). This study found rates of neonatal hyperkalemia to be considerably lower compared to a prior study (14\%vs $36 \%$ ) of neonates with transient, but significant hyperkalemic (serum potassium $>7 \mathrm{mmol} / \mathrm{L}$ )(80). With regards to tacrolimus use in pregnant women with IBD, a single case report has been published of a patient with UC who had a successful pregnancy on maintenance tacrolimus (81). [120]

Lactation-Tacrolimus is transferred in breast milk and its use by breastfeeding mothers is not advised (82). Case reports and small case series of outcomes in breastfed infants, however, have reported no adverse events $(83,84)$.

\section{BIOLOGICS}

\subsection{Infliximab}

Pregnancy-Infliximab is a human-mouse chimeric IgG1 antibody to TNFa. It is used for the induction and maintenance of remission in moderate to severe $\mathrm{CD}$ and UC. It decreases inflammation by binding and neutralizing soluble and membrane-bound TNFa, thereby lowering circulating TNFa levels. Because infliximab crossreacts only with TNFa in humans and chimpanzees, pregnancy safety studies in animal models have not been carried out (79). Nevertheless, it is labeled FDA category B in pregnancy.

Post marketing surveillance studies have found infliximab to be of low risk in pregnancy. Data from the Crohn's Therapy, Resource, Evaluation, and Assessment Tool (TREAT) Registry does not contain any congenital malformations in 36 pregnancies with prior infliximab exposure. The rates of miscarriage $(11.1 \%$ vs. $7.1 \% \mathrm{p}=0.53)$ and neonatal complications ( $8.3 \%$ vs. $7.1 \%, \mathrm{p}=0.78)$ were also not significantly different between infliximab-treated and infliximab-naïve patients (85). Furthermore, the Infliximab Safety Database, a voluntary retrospective data collection instrument for adverse events maintained by the drug's manufacturers, found no difference in expected versus observed outcomes in 96 women with exposure to infliximab during pregnancy (86).

Intentional use of infliximab during pregnancy for the treatment of Crohn's disease was first reported by Mahadevan and colleagues in a series of 10 women who were maintained on infliximab throughout pregnancy (87). All 10 pregnancies resulted in live births, with no congenital malformations. Three preterm births and 1 infant of low birth weight were reported; these events were felt to be due to maternal disease.

Like other $\operatorname{IgG}$ antibodies, infliximab is believed to be actively transported from mother to fetus across the placenta. Transport is mediated by Fc receptors expressed by syncytiotrophoblasts on the surface of the placenta which are bathed in maternal blood. . Fc receptors expressed in the internal vesicles of the syncytiotrophoblasts bind to maternal $\operatorname{IgG}$ and transcytose it to the fetal circulation where it is released at physiological $\mathrm{pH}(88)$. This transplacental transfer of maternal IgG is thought to be most efficient in the second and third trimesters (89). Thus, in an effort to limit fetal exposure to infliximab, some have recommended giving the last dose of infliximab at 32 weeks gestation (90). Whether this strategy reduces the risk for future complications is not known.

Lactation-Breastfeeding while on infliximab is considered to be safe, as studies have not detected infliximab in the breast milk of treated mothers (91). In addition, any infliximab 
that may be transferred should be inactivated by digestive enzymes in the neonate, similar to other large protein molecules (92).

\subsection{Adalimumab}

Pregnancy-Adalimumab is a fully humanized IgG1 antibody to TNFa which is approved for the induction and maintenance of remission of Crohn's disease. Like infliximab, its use in pregnancy has not been associated with an increased risk of congenital malformations or miscarriage $(93,94)$. It is FDA category B in pregnancy.

It is assumed that adalimumab crosses the placenta during the latter half of pregnancy; however, as assays to detect adalimumab are not commercially available, this has not been confirmed (95). Dose adjustments have been recommended for adalimumab use in pregnancy in an effort to reduce fetal exposure. Specifically, it has been recommended that the last dose of adalimumab be given between 34 to 36 weeks gestation when possible (90).

Lactation-Adalimumab has been detected in breast milk at levels lower than $1 \%$ of its level in serum. Given that this small quantity is likely subjected to intestinal proteolytic activity after ingestion, its impact on the systemic immune system of the breastfed infant is likely negligible (96). Thus, at this time adalimumab is considered compatible with breastfeeding (100).

\subsection{Certolizumab pegol}

Pregnancy-Certolizumab is a pegylated Fab' fragment of IgG1 antibody against TNFa which is approved for the treatment of Crohn's disease. Preliminary data suggest that negligible amounts of certolizumab enter the fetal compartment, as serum and cord blood levels of certolizumab in 10 infants exposed in utero were less than $2 \mathrm{mcg} / \mathrm{ml}$, even in infants whose mothers were dosed during the week of delivery (97). Possibly due to the absence of an $\mathrm{Fc}$ fragment, it may not undergo active transport across the placenta (although passive transfer may occur) and therefore may have an advantage for use in pregnancy compared to the other anti-TNFa agents. No changes to the dosing schedule of certolizumab in pregnancy are recommended.

Lactation-Certolizumab pegol is considered compatible with breastfeeding, although human data is lacking (100).

\subsection{Natalizumab}

Pregnancy-Natalizumab is a humanized monoclonal antibody of the IgG4 class that selectively inhibits leukocyte adhesion mediated by $a_{4}$-integrins. Although approved for the treatment of refractory Crohn's disease, its use has been limited by the risk of serious side effects. Progressive multifocal leukoencephalopathy (PML) is an aggressive and often fatal infection of central nervous system glia which has occurred in $0.1 \%$ of patients receiving natalizumab. Its risk is increased in patients exposed to JC virus (JCV). Since asymptomatic detection of PML is rare (most cases are diagnosed after clinical symptoms appear) prescription of natalizumab for IBD has been tepid at best (98). In January 2012 the FDA approved an anti-JCV antibody detection test to determine a patient's JCV status. Patients who screen positive for JCV have a risk profile of approximately 1 in 500 for developing PML versus near zero in patients who are JCV negative. Availability of the JCV detection assay may lead to greater use of natalizumab as potential candidates for the drugand their physicians can better estimate their risk for developing PML (99).

Natalizumab is FDA as category $\mathrm{C}$ in pregnancy. Studies of pregnancy outcomes in natalizumab-treated mothers mainly have involved women with multiple sclerosis, for which 
natalizumab was first approved. Like studies in animal reproductive models, these studies have not found any increased risk of teratogenicity. Nevertheless, according to a recent position statement by the World College of Gastroenterology, the safety of natalizumab in pregnancy should be considered unknown as "the agent is too new for adequate supportive data and there are no drugs of similar mechanism with which to compare it."(100). Furthermore, it is recommended that women treated with natalizumab use sufficient contraception or stop the drug 3 months prior to conception (101).

Lactation-Natalizumab is not recommended during breastfeeding due to lack of safety data.

\section{EXPERT COMMENTARY}

Drugs which are used to treat IBD during pregnancy and lactation may be divided into those which are absolutely contraindicated and those which are considered to have a strongly positive benefit-to-risk ratio. With the exception of methotrexate and thalidomide, most of the standard pharmacologic agents used in the treatment of IBD can be continued prior to and during pregnancy. Nevertheless, prescribers of these agents as well as patients should be aware that long-term safety data are lacking. That is, although no significant evidence for teratogenic effects in human fetuses from thiopurines, calcineurin inhibitors, anti-TNFa agents, or natalizumab exists, the possibility of long-term sequelae from in utero exposure to these agents, such as increased risks for childhood or adolescent infections or neoplasia is largely unknown. Thus, a conservative strategy is to believe that none of the immunomodulators or biologics used to treat IBD have zero risk in pregnancy.

At present, potential risks associated with use of any IBD medication in pregnancy must be weighed against the benefits to the health of the patient and the newborn. There is evidence to suggest that discontinuation of the medications needed to maintain remission at any stage of pregnancy may lead to reactivation of disease which may carry with it an increased risk for an adverse pregnancy outcome (102). Thus, as the dictum "healthy mother, healthy baby" appears to apply to women with IBD, we generally agree with continuation of medication prior to and during pregnancy.

With regards to specific immunomodulators and biologics for the treatment of IBD in pregnancy and lactation, we offer the following opinions:

1. Women who are on a stable dose of azathioprine or 6-MP prior to conception should be continued at that dose during pregnancy. Intrauterine exposure to 6-TGN may be minimized by therapeutic drug monitoring of the mother during pregnancy (40).

We do not recommend either the initiation of a thiopurine during pregnancy or dose escalation during pregnancy, given the unpredictable nature of thiopurine-induced leukopenia and pancreatitis. Women who insist on stopping or decreasing the dose of these drugs prior to pregnancy should be advised to wait 3 months before attempting conception to ensure adequate washout of the drug and to assess disease activity following the dose changes.

Although further data are needed, breastfeeding appears to be safe in women exposed to thiopurines. The benefits of breastfeeding likely outweigh the potential risks of neonatal exposure to low levels of thiopurine metabolites.

Vaccination safety in infants exposed to thiopurines in utero or via breastmilk is largely unknown; however, it is possible that these children may have an 
inadequate response to vaccines and possibly develop overt illness with live virus vaccine (103). Studies in this area are needed.

2. Methotrexate and thalidomide should be discontinued at least 6 months prior to attempting conception by women and not be restarted until lactation has been completed. Men taking methotrexate should stop the drug at least 3 months before conception.

3. Cyclosporine should be considered as an alternative to colectomy in a pregnant woman hospitalized with steroid-refractory UC. Initiation of infliximab in this setting, however, may be more favorable given the side effect profile of cyclosporine. Women who are started on cyclosporine during pregnancy should be advised not to breastfeed.

4. Women with IBD who require an anti-TNFa to maintain disease remission should continue it during pregnancy. For pregnant women with Crohn's disease who require treatment with an anti-TNFa or women who desire pregnancy, initiation of certolizumab pegol should be considered because transplacental transfer of this agent may be lower than for the other approved anti-TNFa agents. Switching patients who are stable on one anti-TNFa to certolizumab pegol during pregnancy, however, is not recommended, as a patient responding to one agent may not respond to another.

Dose adjustments of infliximab and adalimumab should be considered in the third trimester to minimize fetal exposure to these agents. One strategy is to give the final dose of infliximab at 32 weeks gestation and the final dose of adalimumab between 34 and 36 weeks gestation, if the mother's disease status allows. Both drugs can be re-initiated immediately post-partum even if the mother chooses to breastfeed.

Infants exposed to infliximab and adalimumab in utero should not receive any live virus vaccines for the first 6 months of life, given the possibility of immunosuppression in this population and the possibility for vaccine-induced infection $(104,105)$.

\section{CONCLUSION}

As IBD frequently occurs in persons during their reproductive years, many patients will face difficult decisions regarding medication use during pregnancy. Because the FDA currently provides only limited guidance regarding the safety of IBD-medications in pregnancy and lactation, providers should be aware of the data that either support or discourage the use of a given agent. They should also consider the disease activity of their patient when making recommendations regarding medication use in pregnancy and lactation. To determine whether a drug is of sufficiently low risk to be considered safe in pregnancy will require data from future longitudinal studies of children and adults exposed in utero.

\section{Acknowledgments}

Preparation of this manuscript was supported by Award Number K12HD055894 from the Eunice Kennedy Shriver National Institute of Child Health and Human Development (SS). The content is solely the responsibility of the authors and does not necessarily represent the official views of the Eunice Kennedy Shriver National Institute of Child Health \& Human Development or the National Institutes of Health.

\section{BIBLIOGRAPHY}

1. Garland CF, Lilienfeld AM, Mendeloff AI, et al. Incidence rates of ulcerative colitis and Crohn's disease in fifteen areas of the United States. Gastroenterology. 1981; 81:1115. [PubMed: 7286589] 
2. Calkins BM, Mendeloff AI. Epidemiology of inflammatory bowel disease. Epidemiol Rev. 1986; 80:60. [PubMed: 3533585]

3. Norgard B, Hundborg HH, Jacobsen BA, et al. Disease activity in pregnant women with Crohn's disease and birth outcomes: a regional Danish cohort study. Am J Gastroenterol. 2007; 102:19471954. [PubMed: 17573787]

4. Mahadevan U, Sandborn WJ, Li DK, Hakimian S, et al. Pregnancy outcomes in women with inflammatory bowel disease: a large community-based study from northern California. Gastroenterology. 2007; 133:1106-1112. [PubMed: 17764676]

5. Food and Drug Adminstration. Regulations. 1980; 44:37434-37467.

6. http://www.fda.gov/Drugs/DevelopmentApproval-Process/DevelopmentResources/Labeling/ ucm093311.htm

7. Colombel JF, Sandborn WJ, Reinisch W, et al. Infliximab, Azathioprine, or Combination Therapy for Crohn's Disease. N Engl J Med. 2010; 362:1383-1395. [PubMed: 20393175]

8. Diav-Citrin O, Park YH, Veerasuntharam G, et al. The safety of mesalamine in human pregnancy: a prospective controlled cohort study. Gastroenterology. 1998; 114:23-28. [PubMed: 9428214]

9. Mahadevan U. Fertility and pregnancy in the patient with inflammatory bowel disease. Gut. 2006 Aug; 55(8):1198-1206. [PubMed: 16849349]

10. Levi AJ, Fisher AM, Hughes K, et al. Male infertility due to sulphasalazine. Lancet. 1979; 2:276278. [PubMed: 88609]

11. Collen MJ. Azulfidine-induced oligospermia. Am J Gastroenterol. 1980; 74:441-442. [PubMed: 6112875]

12. Ragni G, Biancho Porro G, Ruspa M, et al. Abnormal Semen Quality and Low Serum Testosterone in Men with Inflammatory Bowel Disease Treated for a Long Time with Sulfasalazine. Andrologia. 1984; 16:162-167. [PubMed: 6146274]

13. Mogadam M, Dobbins WO, Korelitz BI, et al. Pregnancy in inflammatory bowel disease: effect of sulfasalazine and corticosteroids on fetal outcome. Obstetrical \& Gynecological Survey. 1981; 36:385-386.

14. Carmichael SL, Shaw GM. Maternal corticosteroid use and risk of selected congenital anomalies. Am J Med Genet. 1999; 86:242-244. [PubMed: 10482873]

15. Carmichael SL, Shaw GM, Ma C, et al. Maternal corticosteroid use and orofacial clefts. Am J Obstet Gynecol. 2007; 197:585-587. [PubMed: 18060943]

16. Czeizel AE, Rockenbauer M. Population-based case-control study of teratogenic potential of corticosteroids. Teratology. 1997; 56:335-340. [PubMed: 9451758]

17. Källén B. Maternal drug use and infant cleft lip/palate with special reference to corticoids. Cleft Palate Craniofac J. 2003; 40:624-628. [PubMed: 14577813]

18. Pradat P, Robert-Gnansia E, Di Tanna GL, et al. First trimester exposure to corticosteroids and oral clefts. Birth Defects Res A Clin Mol Teratol. 2003; 67:968-970. [PubMed: 14745915]

19. Rodríguez-Pinilla E, Martinez-Frias ML. Corticosteroids during pregnancy and oral clefts: a casecontrol study. Teratology. 1998; 58:2-5. [PubMed: 9699238]

20. Muirhead N, Sabharwal AR, Rieder MJ, et al. The outcome of pregnancy following renal transplantation -- the experience of a single center. Transplantation. 1992; 54:429-432. [PubMed: 1412722]

21. Laskin CA, Bombardier C, Hannah ME. Prednisone and Aspirin in Women with Autoantibodies and Unexplained Recurrent Fetal Loss. N Engl J Med. 1997; 337:148-153. [PubMed: 9219700]

22. Al Hadithy AFY, De Boer KNH, Derijks, et al. Thiopurines in inflammatory bowel disease: pharmacogenetics. Dig Liver Disease. 2005; 37:285-292.

23. Cuffari C, Li DY, Mahoney J, et al. Peripheral blood mononuclear cell DNA 6-thioguanine metabolite levels correlate with decreased interferon-gamma production in patients with Crohn's disease on AZA therapy. Dig Dis Sci. 2004; 49:133-137. [PubMed: 14992447]

24. Githens JH, Rosenkrantz JG, Tunnock SM. Teratogenic effects of azathioprine (Imuran). J Pediatr 1065. 66:959-961.

25. Rosenkrantz JG, Githens JH, Cox SM, Kellum DL. Azathioprine (Imuran) and pregnancy. Am J Obstet Gynecol. 1967; 97:387-394. [PubMed: 6017413] 
26. Polifka JE, Friedman JM. Teratogen Update: Azathioprine and 6-Mercaptopurine. Teratology. 2002; 65:240-261. [PubMed: 11967923]

27. Githens JH, Rosenkrantz JG, Tunnock SM. Teratogenic effects of AZP (Imuran). J Pediatr. 1965; 66:561-595.

28. Rosenkrantz JG, Githens JH, Cox SM, et al. AZP (Imuran) and pregnancy. Am J Obstet Gynecol. 1967; 96:387-394. [PubMed: 6017413]

29. Thiersch JB. The effect of 6-mercaptopurine on the rat fetus and on reproduction of the rat. Ann NY Acad Sci. 1954; 60:220-227. [PubMed: 14350527]

30. McKay DB, Josephson MA. Pregnancy in recipients of solid organs--effects on mother and child. N Engl J Med. 2006; 354:1281-1293. [PubMed: 16554530]

31. Polifka JE, Friedman JM. Teratogen update: azathioprine and 6-mercaptopurine. Teratology. 2002; 65:240-261. [PubMed: 11967923]

32. Norgard B, Pedersen L, Fonager K, et al. Azathioprine, mercaptopurine and birth outcome: a population-based cohort study. Aliment Pharmacol Ther. 2003; 17:827-834. [PubMed: 12641505]

33. Francella A, Dyan A, Bodian C, et al. The safety of 6-mercaptopurine for childbearing patients with inflammatory bowel disease: a retrospective cohort study. Gastroenterology. 2003; 124:9-17. [PubMed: 12512024]

34. Alstead EM, Ritchie JK, Lennard-Jones JE, et al. Safety of azathioprine in pregnancy in inflammatory bowel disease. Gastroenterology. 1990; 99:443-446. [PubMed: 2365192]

35. Khan ZH, Mayberry JF, Spiers N, et al. Retrospective case series analysis of patients with inflammatory bowel disease on azathioprine A district general hospital experience. Digestion. 2000; 62:249-254. [PubMed: 11070408]

36. Cleary BJ, Kallen B. Early pregnancy azathioprine use and pregnancy outcomes. Birth Defects Res A Clin Mol Teratol. 2009; 85:647-654. [PubMed: 19343728]

37. Van Os EC, Zins BJ, Sandborn WJ, et al. Azathioprine pharmacokinetics after intravenous, oral, delayed release oral and rectal foam administration. Gut. 1996; 39:63-68. [PubMed: 8881811]

38. Sandborn WJ. Azathioprine: state of the art in inflammatory bowel disease. Scand J Gastroenterol Suppl. 1998; 225:92-99. [PubMed: 9515759]

39. Zimm S, Collins JM, Riccardi R, et al. Variable bioavailability of oral mercaptopurine. Is maintenance chemotherapy in acute lymphoblastic leukemia being optimally delivered? N Engl J Med. 1983; 308:1005-1009.

40. Boer NKH, Jarbandhan SVA, de Graaf P, et al. Azathioprine Use During Pregnancy: Unexpected Intrauterine Exposure to Metabolites. The American Journal of Gastroenterology. 2006; 101:1390-1392. [PubMed: 16771965]

41. Briggs, GG.; Freeman, RK.; Yaffe, SJ., editors. Drugs inPregnancy and Lactation. 3rd ed. Baltimore: Williams and Wilkins; 1990.

42. Lemann M, Mary JY, Colombel JF, et al. A randomized double-blind, controlled withdrawal trial in Crohn's disease patients in long-term remission on azathioprine. Gastroenterology. 2005; 128:1812-1818. [PubMed: 15940616]

43. Christensen LA, Dahlerup JF, Nielsen MJ, et al. Azathioprine treatment during lactation. Aliment Pharmacol Ther. 2008 Nov 15; 28(10):1209-1213. Epub 2008 Aug 30. [PubMed: 18761704]

44. Sau A, Clarke S, Bass J, et al. Azathioprine and breastfeeding: is it safe? BJOG. 2007 Apr; 114(4): 498-501. Epub 2007 Jan 25. [PubMed: 17261122]

45. Feagan BG, Rochon J, Fedorak RN. Methotrexate for the Treatment of Crohn's Disease. N Engl J Med. 1995; 332:292-297. [PubMed: 7816064]

46. Kalb RE, Strober B, Weinstein G. Methotrexate and psoriasis: 2009 National Psoriasis Foundation Consensus ConferenceJ Am Acad Dermatol. 2009; 60:824-837.

47. Briggs, GGFR.; Yaffe, SJ. Drugs in Pregnancy and Lactation. 7th ed. Lippincott: Williams, Wilkins; 2005.

48. Mahadevan U, Kane SV. American Gastroenterological Association Institute technical review on the use of gastrointestinal medications in pregnancy. Gastroenterology. 2006; 131:283-311.

[PubMed: 16831611] 
49. Lloyed ME, Carr M, McElhatton P. The effect of methotrexate on pregnancy and lactation. QJM. 1999; 92(10):551-563. [PubMed: 10627876]

50. Sussman A, Leonard JM. Psoriasis, methotrexate and oligospermia. Arch Dermatol. 1980; 116:215-217. [PubMed: 7356357]

51. French AE, Koren G. Effect of methotrexate on male fertility. Can Family Phys. 2003; 49:577578.

52. El-Beheiry A, El-Mansy E, Kamel N, et al. Methotrexate and fertility in men. Arch Androl. 1979; 3:177-179. [PubMed: 518200]

53. Hirsh A. Male subfertility. BMJ. 2003; 327:669-72. [PubMed: 14500443]

54. Kalb RE, Strober B, Weinstein G. Methotrexate and psoriasis: 2009 National Psoriasis Foundation Consensus Conference. J Am Acad Dermatol. 2009; 60:824-837. [PubMed: 19389524]

55. Johns DG, Rutherford LD, Keighton PC, et al. Secretion of methotrexate into human milk. Am J Obstet Gynecol. 1972; 112:978-980. [PubMed: 5042796]

56. Committee on drugs, American Academy of Pediatrics. The transfer of drugs and other chemicals into human milk. Pediatrics. 1994; 93:137-150. [PubMed: 8265310]

57. Ehrenpreis ED, Kane SV, Cohen LB, et al. Thalidomide therapy for patients with refractory Crohn's disease: an open-label trial. Gastroenterology. 1999; 117:1271-1277. [PubMed: 10579967]

58. Vasiliauskas EA, Kam LY, Abreu-Martin MT, et al. An open-label pilot study of low-dose thalidomide in chronically active, steroid dependent Crohn's disease. Gastroenterology. 1999; 117:1278-1287. [PubMed: 10579968]

59. Fishman SJ, Feins NR, D’Amato RJ, et al. Thalidomide Therapy for Crohn's Disease (letter). Gastroenterology. 2000; 119:596-602. [PubMed: 10960273]

60. Organization of Teratology Information Specialists. [Accessed February 10, 2012] Thalidomide and pregnancy. http://www.otispregnancy.org/files/thalidomide.pdf

61. Zeldis JB, Williams BA, Thomas SD, et al. S.T.E.P.S.: a comprehensive program for controlling and monitoring access to thalidomide. Clin Ther. 1999; 21:319-330. [PubMed: 10211535]

62. Lary JM, Daniel KL, Erickson JD, et al. The return of thalidomide: can birth defects be prevented? Drug Saf. 1999; 21:161-169. [PubMed: 10487395]

63. Kountouras J, Zavos C, Chatzopoulos D. Immunomodulatory benefits of cyclosporine A in inflammatory bowel disease. J Cell Mol Med. 2004; 83:317-328. [PubMed: 15491507]

64. Ina K, Kusugami K, Shimada M, et al. Suppressive effects of cyclosporine A on neutrophils and T cells may be related to therapeutic benefits in patients with steroid-resistant ulcerative colitis. Inflamm Bowel Dis. 2002; 81:1-9. [PubMed: 11837932]

65. Lichtiger S, Present DH, Kornbluth A, et al. Cyclosporine in severe ulcerative colitis refractory to steroid therapy. N Engl J Med. 1994; 330:1841-1845. [PubMed: 8196726]

66. Garcia-Lopez S, Gomollon-Garcia F, Perez-Gisbert J. Cyclosporine in the treatment of severe attack of ulcerative colitis: a systematic review. Gastroenterol Hepatol. 2005; 28:607-614. [PubMed: 16373009]

67. Sandborn WJ. Cyclosporine in ulcerative colitis: state of the art. Acta Gastroenterol Belg. 2001; 64(2):201-204. [PubMed: 11475136]

68. Ramsey-Goldman R, Schilling E. Immunosuppressive drug use during pregnancy. Rheum Dis Clin North Am. 1997; 23:149-167. [PubMed: 9031380]

69. Petri M. Immunosuppressive drug use in pregnancy. Autoimmunity. 2003; 36:51-56. [PubMed: 12765471]

70. Bar, Oz B.; Hackman, R.; Einarson, T., et al. Pregnancy outcome after cyclosporine therapy during pregnancy: a meta-analysis. Transplantation. 2001; 71:1051-1055. [PubMed: 11374400]

71. Bertschinger P, Himmelmann A, Risti B, et al. Cyclosporine treatment of severe ulcerative colitis during pregnancy. Am J Gastroenterol. 1995; 90:330. [PubMed: 7695771]

72. Jayaprakash A, Gould S, Lim AG, et al. Use of cyclosporin in pregnancy. Gut. 2004; 53:13861387. [PubMed: 15306605]

73. Branche J, Cortot A, Bourreille A, et al. Cyclosporine treatment of steroid-refractory ulcerative colitis during pregnancy. Inflamm Bowel Dis. 2009; 15:1044-1048. [PubMed: 19137604] 
74. Munoz-Flores-Thiagarajan KD, Easterling T, Davis C, et al. Breastfeeding by a cyclosporinetreated mother. Obstetrics \& Gynecology. 2001; 97(5):816-818. [PubMed: 11336764]

75. Moretti ME, Sgro M, Johnson DW, et al. Cyclosporine excretion into breast milk. Transplantation. 2003; 75:2144-2146. [PubMed: 12829927]

76. Committee on Drugs. American Academy of Pediatrics. The transfer of drugs and other chemicals into human milk. Pediatrics. 2001; 108:776-789. [PubMed: 11533352]

77. Seghal SN. Rapamune ${ }^{\circledR}$ (RAPA, rapamycin, sirolimus): mechanism of action immunosuppressive effect results from blockade of signal transduction and inhibition of cell cycle progression. Clinical Biochemistry. 1998; 31:335-340. [PubMed: 9721431]

78. Mihatsch MJ, Kyo M, Morozumi K, et al. The side-effects of cyclosporine-A and tacrolimus. Clin Nephrol. 1998 Jun; 49(6):356-363. Review. [PubMed: 9696431]

79. Gisbert JP. Safety of immunomodulators and biologics for the treatment of inflammatory bowel disease during pregnancy and breast-feeding. Inflamm Bowel Dis. 2010; 16:881-895. [PubMed: 19885906]

80. Jain A, Venkataramanan R, Fung JJ, et al. Pregnancy after liver transplantation under tacrolimus. Transplantation. 1997; 64:559-565. [PubMed: 9293865]

81. Baumgart DC, Sturm A, Wiedenmann B, et al. Uneventful pregnancy and neonatal outcome with tacrolimus in refractory ulcerative colitis. Gut. 2005; 54:1822-1823. [PubMed: 16120758]

82. Grimer M. Pregnancy, lactation and calcineurin inhibitors. Nephrology. 2007; 12:S98-S105. [PubMed: 17316288]

83. Armenti VT, Radomski JS, Moritz MJ, et al. Report from the National Transplantation Pregnancy Registry (NTPR): Outcomes of pregnancy after transplantation. Clin. Transpl. 2003:131-141. [PubMed: 15387104]

84. French AE, Soldin SJ, Soldin OP, et al. Milk transfer and neonatal safety of tacrolimus. Ann. Pharmacother. 2003; 37:815-818. [PubMed: 12773068]

85. Lichtenstein GR, Feagan BG, Cohen RD, et al. Serious infections and mortality in association with therapies for Crohn's disease: TREAT registry. Clin Gastroenterol Hepatol. 2006; 4:621-630. [PubMed: 16678077]

86. Katz JA, Antoni C, Keenan GF, et al. Outcome of pregnancy in women receiving infliximab for the treatment of Crohn's disease and rheumatoid arthritis. Am J Gastroenterol. 2004; 99:23852392. [PubMed: 15571587]

87. Mahadevan U, Kane S, Sandborn WJ, et al. Intentional infliximab use during pregnancy for induction or maintenance of remission in Crohn's disease. Aliment Pharmacol Ther. 2005; 21:733-738. [PubMed: 15771759]

88. Roopenian DC, Akilesh S. FcRn: the neonatal Fc receptor comes of age. Nature Reviews Immunology. 2007; 7:715-725.

89. Simister NE. Placental transport of immunoglobulin G. Vaccine. 2003; 21:3365-3369. [PubMed: 12850341]

90. Mahadevan U. Pregnancy and IBD: how to best communicate risks and benefits to patients and obstetricians. AGA Perspectives. 2011; 7(4):8-9.

91. Kane S, Ford J, Cohen R, et al. Absence of infliximab in infants and breast milk from nursing mothers receiving therapy for Crohn's disease before and after delivery. J Clin Gastroenterol. 2009; 43:613-616. [PubMed: 19142167]

92. Moffatt DC, Bernstein CN. Drug therapy for inflammatory bowel disease in pregnancy and the puerperium. Best Pract Res Clin Gastroenterol. 2007; 21:835-847. [PubMed: 17889811]

93. Vesga L, Terdiman JP, Mahadevan U. Adalimumab use in pregnancy. Gut. 2005; 54:890. [PubMed: 15888806]

94. Mishkin DS, Van Deinse W, Becker JM, et al. Successful use of adalimumab (Humira) for Crohn's disease in pregnancy. Inflamm Bowel Dis. 2006; 12:827-828. [PubMed: 16917239]

95. Beaulieu DB, Kane SV. Inflammatory bowel disease in pregnancy. Gastroenterol Clin N Am. 2011; 10:399-413.

96. Ben-Horin S, Yazvori M, Katz L, et al. Adalimumab Level in Breast Milk of a Nursing Mother. Clin Gastroenterol and Hepatol. 2010; 8:475-476. 
97. Mahadevan U, Abreu MT. Certolizumab Use in Pregnancy: Low Levels Detected in Cord Blood. Gastroenterology. 2009; 136:A-146. (abstract).

98. Clifford DB. Natalizumab and PML: a risky business? Gut. 2008; 57:1347-1349. [PubMed: 18791114]

99. Gorelik L, Lerner M, Bixler S, et al. Anti-JC virus antibodies: Implications for PML Risk Stratification. Ann Neurol. 2010; 68:295-303. [PubMed: 20737510]

100. Mahadevan U, Cucchiara S, Hyams JS, et al. The London Position Statement of the World Congress of Gastroenterology on Biological Therapy for IBD With the European Crohn's and Colitis Organization: Pregnancy and Pediatrics. Am J Gastroenterol. 2011; 106:214-223. [PubMed: 21157441]

101. Hellwig K, Haghikia A, Gold R. Pregnancy and natalizumab: results of an observational study in 35 accidental pregnancies during natalizumab treatment. Mult Scler. 2011 Aug; 17(8):958-963. Epub 2011 May 25. [PubMed: 21613333]

102. Zlatanic J, Korelitz BI, Rajapakse R, et al. Complications of pregnancy and child development after cessation of treatment with 6-mercaptopurine for inflammatory bowel disease. J Clin Gastroenterol. 2003; 36:303-309. [PubMed: 12642735]

103. Mastrobattista JM, Veronica Gomez-Lobo V. Pregnancy after solid organ transplantation. Obstet Gynecol. 2008; 112:919-932. [PubMed: 18827137]

104. Djokanovic N, Klieger-Grossmann C, Pupco A, et al. Safety of infliximab use during pregnancy. Reprod Toxicol. 2011; 32:93-97. [PubMed: 21621603]

105. Janneke van der Woude C, Kolacek S, Dotan I, et al. European evidenced-based consensus on reproduction in inflammatory bowel disease. Journal of Crohn's and Colitis. 2010; 4:493-510. 
Table 1

Food and Drug Administration Categories for the Use of Medications in Pregnancy

FDA Pregnancy Category Interpretation

A

B

$\mathrm{C}$

$\mathrm{D}$

$\mathrm{X}$

Controlled studies in animals and women have shown no risk in the first trimester, and possible fetal harm is remote.

Either animal studies have not demonstrated a fetal risk but there are no controlled studies in pregnant women, or
animal studies have shown an adverse effect that was not confirmed in controlled studies in women in the first trimester.

No controlled studies in humans have been performed, and animal studies have shown adverse events, or studies in humans and animals not available; give if potential benefit outweighs the risk.

Positive evidence of fetal risk is available, but the benefits may outweigh the risk if life-threatening or serious disease.

Studies in animals or humans show fetal abnormalities; drug contraindicated 
Table 2

Medications used to treat inflammatory bowel disease

\begin{tabular}{|c|c|c|c|c|}
\hline \multicolumn{2}{|l|}{ Drug } & FDA Pregnancy Category & Recommendations for Pregnancy & Recommendations for Lactation \\
\hline \multicolumn{2}{|l|}{ Corticosteroids } & $\mathrm{C}$ & $\begin{array}{l}\text { Possible increased risk of oral } \\
\text { clefts with first trimester use; risk } \\
\text { for fetal adrenal insufficiency, } \\
\text { macrosomia, premature rupture of } \\
\text { membranes }\end{array}$ & Compatible \\
\hline \multirow[b]{2}{*}{ Antibiotics } & Metronidazole & B & Safe & Safe \\
\hline & Ciprofloxacin & $\mathrm{C}$ & $\begin{array}{l}\text { Avoid long-term use due as binds } \\
\text { to fetal cartilage and may cause } \\
\text { arthropathy in children }\end{array}$ & $\begin{array}{l}\text { Limited human data; probably } \\
\text { compatible }\end{array}$ \\
\hline \multirow{4}{*}{ Immunomodulators } & Azathioprine/ 6-mercaptopurine & $\mathrm{D}$ & $\begin{array}{l}\text { Probably safe; avoid starting de } \\
\text { novo in pregnancy }\end{array}$ & Probably safe \\
\hline & Thalidomide & $\mathrm{X}$ & $\begin{array}{l}\text { Contraindicated due to } \\
\text { teratogenicity }\end{array}$ & Contraindicated. \\
\hline & Cycloporine & $\mathrm{C}$ & Probably safe & Not recommended \\
\hline & Tacrolimus & $\mathrm{C}$ & Probably safe & Not recommended \\
\hline \multirow{3}{*}{ Anti-TNF agents } & Infliximab & \multirow[t]{3}{*}{$\mathrm{B}$} & \multirow{3}{*}{$\begin{array}{l}\text { Low risk; dose adjust infliximab } \\
\text { and adalimumab in } 3^{\text {rd }} \text { trimester to } \\
\text { minimize fetal exposure }\end{array}$} & \multirow[t]{3}{*}{ Compatible } \\
\hline & Adalimumab & & & \\
\hline & Certolizumab pegol & & & \\
\hline \multicolumn{2}{|l|}{ Natalizumab } & $\mathrm{C}$ & No human data & Not recommended \\
\hline
\end{tabular}

